\title{
Spirit-possession in Theory and Practice- Séances with Tibetan Spirit-mediums in Nepal
}

\author{
By PER-ARNE BERGLIE
}

This paper is a short study of the séances and trance-performances of three Tibetan spirit-mediums ( $d p a^{\prime} b o$ ) from a refugee-community in Nepal.

For each $d p a$ ' bo a summary of personal thoughts and beliefs concerning possession is provided, followed by an example of how a séance was structured. In a concluding section the inner experiences of the mediums during the séance will be related and a few comments given.

For further details on this type of spirit-mediumship and for relevant background-material, the reader is referred to some previous studies by the present author (Berglie 1976, 1978, 1980). The field-work on which this study is based was carried out in a Tibetan refugee-village in Nepal during 1970 and 1971.

\section{dBang phyug}

He was a man about forty years old. He was married and had one son. He was suffering from tuberculosis, but worked as a porter or doing various odd jobs. He was born in Eastern Tibet.

Before he let himself be possessed at a séance, he had to send away his rnam shes, "consciousness". This had to be effected immediately before possession took place, as the moment when the body was "empty", i.e. without rnam shes and before it was possessed by a god, was considered extremely dangerous. Evil spirits and demons of various kinds were always thought to be trying to disturb the séances. In this case a demon could very well seize the opportunity to enter the spirit-medium's "empty" body, pose as a god and thereby create great dangers for the spirit-medium as well as for those seeking help. It was considered equally dangerous if the $d p a^{\prime}$ bo let his rnam shes remain in his body after he had let the god in. Then he would be "half god, half man" and what he said and did could not be trusted.

dBang phyug sent his rnam shes to the mirrors placed on the altar through the "channel", rtsa, opening at the top of the skull. These mirrors 
are considered to be the most important parts of a $d p a^{\prime}$ bo's equipment, as the gods are thought to reside in them during the séance. His rnam shes is then taken care of by Padma 'byung gnas (Padmasambhava).

Essential to an understanding of how possession is thought to take place is the belief in the existence of "channels" in the human body. This is not the place for a study of the very important role played by this belief in Indian medicinal and religious speculation. Suffice it to say that it occurs in most of the Buddhist Tantras and their commentaries (see, e.g., Dasgupta 1958: 153-158; Eliade 1969: 236-241; Govinda 1959: 103, 155, 170, 173; Snellgrove 1957: 88, 90; 1959: 25, 27, $35 \mathrm{ff}$; Stablein 1976: $57 \mathrm{ff}$; Tucci 1961: 108-133; 1970: 72-79; Wayman 1973: 151 f., 192f.; 1977: 65, 205f.). According to this religious physiology the human body, or perhaps rather the "subtle" body the Tantric practician may develop, has a very great number of "channels" or "veins" (nādī, rtsa) of which there are three chief ones. They are Avadhūti ( $d b u$ ma rtsa), Rasanā (ro ma rtsa), and Lalanā (rkyang ma rtsa). The three are united at the base of the genitals from where they run upwards in the body. The central one, dbu ma rtsa, runs straight up to the top of the head, while ro ma rtsa runs to the right and rkyang ma rtsa to the left up to the nostrils. It may be noted that ro ma rtsa is associated with the blood, while dbu ma rtsa is associated with air and rkyang ma rtsa with water (Stablein 1976: $57 \mathrm{ff}$.). dBang phyug's view of these things differed, however, from this literary tradition in a number of ways. Thus, according to him, the three "channels" unite in a point in the middle of the chest with dbu ma rtsa having its opening at the top of the head, ro ma rtsa in the tip of the fourth finger of the left hand, and rkyang $m a$ rtsa in that of the right hand. Furthermore, according to him both $d b u$ ma rtsa and ro ma rtsa are white, while rkyang ma rtsa is red.

It is through these "channels" that possessing gods enter the body of the $d p a$ ' bo. Each 'channel" has at its opening a door (rtsa sgo), which can be opened to let the possessing god in. These doors were often mentioned at the séances with dBang phyug, soon after possession had taken place, together with the names of certain deities. These deities were not necessarily the same at every séance. The pantheon of the $d p a^{\prime}$ ' bo is divided into three classes: Iha, btsan, and klu, and the three "channels" are assigned to members of these classes. dBu ma rtsa was always guarded by a tha, rkyang ma rtsa by a btsan or, less often, by a klu and ro ma rtsa, finally, by a klu more often than by a btsan. The deities mentioned in this connection functioned as guardians of the rtsa-doors with an obligation to make it impossible for demons to enter. During the séances they were called rtsa lam sang mkhan, "cleaners of the rtsa-road", which perhaps indicates that these deities had other functions as well.

Furthermore there were other gods present to guard these "channels". 
Theirs was, moreover, the main responsibility that nothing happened to dBang phyug during possession. They were gnyan chen Thang lha mi dkar rta dkar, here carrying the title rtsa bdag, "Master of the rtsa" and $M a$ sangs rkyang khra mchor bo, with the title rtsa rogs, "Helper of the rtsa(master)". These gods dBang phyug had inherited from elder spirit-mediums in his family. They are, therefore, common to all $d p a^{\prime}$ bos belonging to his lineage.

During the séances, a further number of supernatural beings were mentioned in connection with the "channels" and their protection. They were called rtsa ba'i bla mas, "root-lamas", a term otherwise used to designate a pupil's personal gurus. It is not clear to what degree the semantic ambivalence of the word rtsa has influenced the connection between these figures and the "channels" in the body of the spirit-medium. Nevertheless it is quite clear, that to $d B a n g$ phyug they were powerful protective beings to be invoked just before he let himself be possessed. It is, however, difficult to see any primary connection between these figures, among whom we find the Dalai lama, Karmapa, Padmasambhava, Vajrapāṇi, Hayagrīva, Amitābha and many more, and spirit-medium activities. Perhaps we have here important figures in Tibetan religion, who due to their importance have been connected, in a protective function, to a crucial situation in the ritual of the $d p a$ ' bos. But not only is the initial phase of possession considered dangerous, it is also necessary for the $d p a^{\prime}$ bo to be protected by gods during the whole of the séance. Thus a number of supernatural beings arrive at the séances and place themselves by certain parts of the body of the $d p a^{\prime}$ bo, from where they guard and control proceedings. These gods were usually mentioned soon after dBang phyug had put on his rigs Inga, headdress, but before possession had taken place. The five parts of the body thus serving as abodes were: the top of the skull, the right and the left shoulder, the back (i.e. the part between the shoulder-blades), and the chest (i.e. the heart). Only during one séance was one god mentioned, the latter obviously thought of as guarding the whole of dBang phyug's body. These gods were not the same at every séance. Apart from gods more properly belonging to the pantheon of the $d p a^{\prime} b o s$, we find such prominent figures as Hayagriva guarding the back, and Ye shes mtsho rgyal, the female consort of Padmasambhava, guarding the chest of dBang phyug.

As can be seen from the above, a séance involves rather a large number of gods. In addition to the hundreds of gods attending the séance in the mirrors on the altar, several gods both high-ranking and more obscure play important roles in the ritual.

As an example of what might take place during a typical séance with $d B a n g$ phyug, I will now give extracts from my notes taken at a séance for a 
woman and her grown-up married daughter. The mother thought she had been bitten by a dog infected with rabies, while her daughter had pains in what she thought was her liver. In addition to this, the mother also suffered from headaches. "(6.05 p. m.) dBang phyug has already started to arrange the special séance-altar when I arrive at the house of the sick people. He builds it up in front of the house-altar, which is placed on his right side. During this work he chats with the people present. He has laid out a g.yung drung (svastika) of rice on the shelf on which he now arranges his altar. He fills two small bowls with spags (i.e. rtsam pa, roast-flour, mixed with water or tea) and one with rice, forming the contents to conical gtor mas. The bowl with the gtor ma of rice is placed to the left. In the bowl in the middle, he then places a round metal mirror and, behind it, a stick to which three small $t$ sagle-pictures are attached. These pictures represent, according to dBang phyug, Sa skya gong ma, Guru drag po, and mGon po phyag drug. In the bowl to the left, he then places a stick with pictures of $U$ rgyan rin po che (Padmasambhava) and Karmapa. In the bowl to the right he puts a stick with the picture of dPal ldan lha mo attached. Over these small paintings he then puts a white kha btags and pieces of red cloth. In front of these bowls he then places three smaller ones, the right one filled with tea, the middle one with water to which he adds some milk-powder, and the left one with water. A bundle of white feathers is placed to the far left of the altar and two white conch-shells on either side of the middle bowl. Over the small bowl with tea, a spoon is laid and, finally, a small oil-lamp and some incense-sticks are placed on the altar. Thus the altar has been built up in his customary way. (6.21 p.m.) He starts his introductory prayers, which soon lead on to the invocations proper. A great number of gods belonging to different classes are mentioned by name and asked to come to the place. (6.43 p. m.) The invocations are now concluded, the gods having arrived and installed themselves. dBang phyug chats with the people present in a relaxed and joking way. He then puts on a special séance-shirt and hangs a thin metal mirror around his neck and ties a piece of red cloth around his head. (6.53 p. m.) He lifts his headdress with both hands and holds it up in front of him, singing the names of the five $m k h a$ ' ' $g r o$ mas (dākinīs), who during the séance are associated with the five lobes of the rigs lnga. (6.56 p. m.) He fastens his headdress to his head with two strings and then starts to sing, accompanying himself with his small drum and his flat bell, gshang. The drumming is steadily becoming more intense and violent and he jumps several times on the bench where he is sitting cross-legged. Suddenly he jumps out onto the floor, crying "phat ' three times and starting to dance. After a short time he jumps back up on the bench, where he kneels turning to the altar. He now sings about the gods in the mirror and about the cave at 
Mount Targo (on this cave and its importance to the dpa' bos, see Berglie 1980). After some time, a kha btags is put over dBang phyug's headdress, as a greeting to the possessing god, in spite of the fact that no one in the room has heard the god introduce himself. The task he has to carry out is then presented to the god by the man appointed as intermediary. The god makes a few comments on this and the intermediary answers. Then the god starts to make rather harsh and sarcastic comments on a séance which $N y i$ ma don grub, another $d p a^{\prime}$ bo, held a few days ago for his sick brother (see below). Nyi ma don grub, who is present, listens to the god with a troubled look on his face. The god says that the young man has not been cured. (7.22 p. m.) dBang phyug is now going to perform rtsis, which is the dpa'bos' designation of the method of drum divination they commonly used. He puts his drum in front of himself on the bench and places seven grains of rice on the drumskin. When he then asks the gods to carry out the divination, the grains move with sudden jumps on the drumskin. After that he carries out another divination, where he asks the gods to make the grains rotate on the drumskin. The grains accordingly started to rotate clock-wise rather fast. These divinations were made for the prognosis of Nyi ma don grub's brother's illness and the result was auspicious: he was going to get well. (7.25 p.m.) The god talks about the divination and about the nature of the illness. The intermediary tries to say something but is rebuffed by the god. The god, however, soon resumes the singing and asks the elder to sit down in front of him. She does so. The god is now rather irritated for some reason or other. He calms down and starts to drum. Then he takes his horn, rkang gling and strikes the woman three times over her right shoulder crying "phat". (8.00 p.m.) The god now explains the course of the illness and complains about being asked to cure at this early stage. During his singing, the god also expresses great displeasure at the behaviour of the intermediary, who is subsequently replaced by another man. dBang phyug alternates between song and talk, when he now mentions several of the supernatural animals which can possess the $d p a^{\prime}$ bo to effect the actual removal of the illness from the patient. $(8.19 \mathrm{p} . \mathrm{m}$.) The curing animal now takes possession of dBang phyug. Some believe it is Zangs spyang dmar po, "Red Copper-Wolf" (this proves to be wrong, see below). The woman has bared her back and a piece of red cloth is put over her shoulder. dBang phyug moves his horn over her back, arms, and head. Then he blows his horn once. Then he sucks several times through the horn with its opening placed at various points of the woman's back and neck. He then spits into a small bowl of water. Nothing, however, is visible in the water when it is inspected by the people present. The bowl is now filled with fresh water. Then he again sucks through his horn, moving it around her shoulder. He 
again spits in the bowl, but still nothing is to be seen. dBang phyug then moves his drum over the shoulder and neck of the woman. He drums violently. Then he proceeds to suck from her head, at the same time moving his drum, which he holds in his right hand, over the woman's back. When he now spits into the water, some black colour is seen. He then drinks several bowls of water handed to him by the intermediary. The animal has now left dBang phyug's body and the god has resumed control. He talks about what has happened and what has been sucked out. He asks the onlookers if it is a lump or if it has fallen apart in the water and, if that is the case, if all parts are there. The god asks everyone present to look closely and carefully. The intermediary then tells the god what is to be seen in the bowl. The god also asks us to inspect the horn and the hands and mouth of "the red one" (dmar po, i.e. dBang phyug), to see whether any cheating has taken place. No one, of course, does this. Then he tells us that it was a bird, mtho nam mkha'i Khyung chen + dernga, who sucked out and thus cured the illness. $(8.37$ p.m.) The god now continues talking and singing about various illnesses and their symptoms. He is then going to treat the younger woman, who now sits in front of him. He says that he cannot do much for her but that he will try just to ease her mind. If there is anything to be sucked out, he will take care of it. He also asks about her symptoms; has she lost her appetite, does her back ache, has she pains in the liver? The intermediary afirms all of this. The god then enumerates a number of illnesses which correspond to the symptoms and says, as far as can be understood (see below), that he is going to send for Zangs spyang dmar po. He then hits her three times over the back with his horn and cries "phat". The woman now bares the upper part of her body and the piece of red cloth is put on her back. dBang phyug starts a fast and violent drumming and tinkling and the supposed wolf arrives sniffing and howling. He then pats her lightly on her back with the drum. Thereupon he sucks twice through the drum, one edge of the drum in his mouth and the opposite edge against the piece of red cloth. When he spits into the small bowl of water, a faint red colour can be seen dissolving. He then places the drum against the woman's chest, at the same time pressing his horn against her back. The red cloth is now put between her breasts. dBang phyug then suddenly and very quickly grabs the cloth and thrusts it into his mouth. He takes it out and holds it up; a black lump in the wrinkled cloth is the removed illness. The lump is about $5-6 \mathrm{~mm}$ long and $2 \mathrm{~mm}$ thick. After the lump has been shown to everyone, dBang phyug sucks through his horn from a point between the woman's breasts. At the same time he is patting her on the back with his drum. He then spits out what looks like saliva mixed with blood on the drumskin. Then the animal leaves him and the god returns. He 
immediately starts with an explanation of what has been done. During the singing he tears a piece of yellow cloth into ribbons, one of which he gives to the elder woman and one to the younger. He says they should wear these ribbons as a protection and as a blessing. (9.00 p. m.) The task has now been carried out and the gods are ready to leave. dBang phyug mentions them one by one and they all receive a drop of tea, thrown by one of the onlookers from the small bowl on the altar. $(9.15 \mathrm{p} . \mathrm{m}$.) The gods have now all been formally taken leave of and the concluding part of the séance, the so-called rigs lnga-game, the playing with the headdress ( i rtsed), starts. It soon becomes rather violent, dBang phyug shaking his head and body while singing to a very rapid and loud drumming. (9.35 p.m.) He now unties one of the two strings with which the headdress is held onto his head and continues the agitated movements. He sings that he is going to ask the leaving gods to tear feathers from their mounts, the thang $d k a r$-birds, as they fly away. Soon small white feathers are falling in the room and the onlookers are eager to catch them before they reach the ground, as they are considered to be auspicious. Again dBang phyug pulls at one of the wings of his headdress, as if to show how well it is kept on his head by the $m k h a^{\text {' }}$ 'gro ma (the rigs Inga is believed to be guarded and kept on the head on the $d p a$ ' bos by one or two of these female deities.). The "play" continues while feathers swirl in the room. Then dBang phyug makes a short stop, while he moves his head as if following the flight of the birds. $(10.06 \mathrm{p} . \mathrm{m}$.) dBang phyug shakes violently, the drumming now has an intense and pulsating rhythm. (10.19 p. m.) With his left hand he now picks up a piece of grey cloth. The headdress is sliding slowly backwards on his head as the "play" nears its end. Finally, it slides off his head and stays around his neck with the wings spreading over his shoulders. He puts the grey cloth over his face and drums violently. (10.24 p.m.) The drum and the gshang fall out of his hands, the séance is over. For a short while dBang phyug sits shrunken on the bench but soon recovers and starts to collect his equipment. As he is folding his headdress two men from the audience step forward and ask to be blessed with it. They kneel in front of him and dBang phyug puts his folded headdress on their heads and says a prayer. Most of the onlookers have now left the house and those of us who remain are offered some food. There is now a relaxed conversation on what has happened that evening and dBang phyug is informed about the proceedings."

\section{Sri gcod}

He was about thirty-two years old, married and with one child. He was born in North-Eastern Tibet. He worked mainly as a porter. 
Sri gcod was very reluctant to tell anything about how he conceived the possession. There are a few hints that his ideas differed from those of dBang phyug but nothing can be said with certainty. As in the case of $d$ Bang phyug, Sri gcod must send away his rnam shes before the possessing god enters. It is then taken care of by a certain deity, the identity of whom Sri gcod did not wish to reveal. He maintained, however, that it was not the whole god, so tc speak, who entered his body but just the god's rnam shes.

The three "channels" through which possession took place according to dBang phyug were never mentioned at the séances of Sri gcod as far as could be heard. Instead the rtsas were spoken of as being tripartite and the three parts as guarded by three gods: a lha, a btsan, and a klu.

Nor did Sri gcod want to speak about his rtsa bdag but others claimed that it was the god $A$ bse rgyal ba + dung dmar, who carried out this function for Sri gcod. This, they said, could be understood from the fact that Sri gcod emitted a loud piping sound during the dance just after having become possessed. The term rtsa ba'i bla ma was also heard at Sri gcod's séances but whom he meant specifically is not known.

At one séance, in addition, a list of deities attending and guarding the five parts of his body, as mentioned in the case of dBang phyug, could be heard. Of these gods, mkha' 'gro Ye shes mtsho rgyal, who protected his back, is perhaps the most well-known.

As an example of how his séances were structured, extracts from notes made at one of them are given here.

"When I arrive, the altar has already been built up. It consists of three flat wooden bowls, on which gtor mas have been constructed. The left one is made of rice, the two others of spags. In front of these bowls, two smaller bowls have been placed, one filled with water and the other with milk. Between them is an oil-lamp. At the front is a bowl with tea over which a spoon has been laid. In each of the gtor mas is a stick to which tsagle-pictures are attached. Padma 'byung gnas to the left, Guru drag po in the centre, and mGon po ber nag to the right. A kha btags is stretched over the three small paintings. In the centre bowl there are two metal mirrors of circular shape, a smaller one in front of a larger one. On the altar there are also burning incense-sticks and, on the floor, a larger bowl with burning incense. Sri gcod is sitting on a cushion on the floor with the altar on his left side. The séance, which is held on my account, takes place in the temple room of the small Karma bka' brgyud pa monastery in the village. The onlookers, mostly novices, are sitting behind Sri gcod. (7.50 p. m.) He whirls his drum for a few seconds, then starts to sing the invocations. During the singing he slowly rocks the upper part of his body. All the gods 
arrive in due order to the mirrors on the altar. When the invocations are finished he attaches a piece of red cloth to his head and starts to sing again. His voice is now louder and harsher and the rocking more violent. After a few minutes Sri gcod stops singing, having almost yelled the last words. Suddenly he laughes derisively; the god has taken possession of him. He puts on his headdress and sings for a short while. Then he jumps up to a standing position and executes a slow dance, standing on one leg at a time. He dances up to me, then to the lama, who is sitting on my left. The lama sprinkles him with a few drops of water with his peacock's feather. Then Sri gcod dances up to the temple altar, making a sort of circumambulation in the room. After that he again moves up to the lama and kneels there. The man appointed as intermediary now puts my questions to the god, Chos skyong + chag med. The questions concern my relatives in Sweden. The intermediary is also blessed by the lama. During the questioning the intermediary puts a kha btags over Sri gcod's headdress. The god then starts to sing, explaining that he never before has been consulted by a foreigner and that it will be hard to give any answers. Then he starts to talk about Sweden, but unfortunately it is difficult to hear the details. Then he moves back and sits down in front of his altar. The god now says that a drum divination has to be performed in order to find the answers to my questions. This he performs in the following way. He holds his drum, with one of the drumskins upwards, in his right hand and lets a few grains of rice fall down on the skin from his left hand. From the configurations of the grains on the drumskin he receives the answers. This is repeated until all questions have been answered. The answers are all positive and reassuring. During the procedure he keeps his eyes closed, opening them only occasionally and showing the whites of the eyes. When he now starts to sing, he mentions things of more general interest, explaining the various parts of the séance. Among other things he says that the dance chases away the demons and he also gives some details about the first four $d p a$ ' bos in Tibet, living in the time of Padma 'byung gnas. Then the gods prepare to leave the place. Sri gcod mentions them all by name and the intermediary sprinkles a few drops of tea for everyone. Then the mkha' 'gro ma, who has kept his headdress on his head during the séance, is asked to loosen her grip and the headdress begins to slip backwards slowly. $(9.20 \mathrm{p}$. m.) The headdress falls off and he rather abruptly stops drumming. He hiccups once and slumps but remains sitting. He seems very tired but soon begins to gather his equipment. He asks the lama if he has done a good performance. On receiving an affirmative answer he finishes dismounting the altar." 


\section{Nyi ma don grub}

He was twenty-six years old and unmarried. He was born in Northern Tibet. He worked as a carpet-weaver in the handicraft centre in the village.

He was a friendly informant but, as he was not yet fully established as a spirit-medium, he had not completed his training. This must be remembered, as there are a number of inconsistencies in the material emanating from him, in spite of his continuous additions and corrections during interviews and informal conversations. He was clearly a very creative personality in a formative period of his life when I met him. The period of calling was not yet over and his behaviour accordingly was frequently rather eccentric.

Like dBang phyug and Sri gcod, Nyi ma don grub maintained that he had to send away his rnam shes before the god entered his body. He sent it to the altar, where it was taken care of by $m k h a$ ' 'gro Ye shes misho rgyal during the duration of the possession. But, as he was not yet a fully trained $d p a$ ' bo, he sometimes carried out special séances under the supervision of his teacher Sri gcod. Then his rnam shes was taken care of by his teacher.

Concerning what happened when he became possessed, he gave apparently contradictory versions on different occasions. At one time he said that first a member of the lha-class arrives through dbu ma rtsa and stays in the head, then two members of the btsan-class arrived through ro ma rtsa and rkyang ma rtsa and stay in his chest and the lower part of his body, respectively. After these two another two gods arrive directly at his shoulders and stay there. Finally the two female deities in charge of his headdress arrive. One of them stretches the string which is tied around his head and the other sees to it that the knot does not become untied.

On another occasion, however, he said that the members of the lha-class always use the rtsa opening in his left hand, while members of both the btsan- and klu-class use the rtsa to the right. After entering, the members of the lha-class move upwards to the upper part of his body and the head, the members of the btsan-class stay in the middle part, while the members of the klu-class move downwards to his legs.

On a third occasion he said that members of the $l$ ha- and $k l u$-class never enter the body of a spirit-medium, they only send their "light", 'od gzer, into it. Only members of the btsan-class can possess a $d p a$ ' bo, he maintained.

From the tape-recordings of séances with Nyi ma don grub, it could be established that the lha-class was linked to dbu ma rtsa, the btsan-class to ro ma rtsa, and the klu-class to rkyang ma rtsa. Furthermore, several lists 
of deities associated with the five parts of the body of the $d p a^{\prime}$ bo could be enumerated with the help of these tape-recordings. Among these gods perhaps Pha dam pa sangs rgyas, a well-known historical figure, may be mentioned.

Below follows an extract from notes taken at one of the séances with $N y i$ ma don grub that I attended. It was neld on account of his sick younger brother. This was the séance for which he later would receive such heavy criticism from the god during one of $d B$ ang phyug's séances (see above).

" (5.40 p. m.) I arrive at the house as Nyi ma don grub is constructing his altar. As he has not much equipment of his own, he has borrowed most of the items from $d B$ ang phyug and he builds the altar in roughly the same way as he does. As for the tsagle-paintings, however, he has put two on a stick in the left gtor ma depicting, according to him, Phyag na rdo rje (Vajrapāni) and Sa skya gong ma; two on a stick in the bowl in the centre representing Karmapa and $\mathrm{lHa}$ btsan and two on a stick in the right bowl, depicting mkha' 'gro Ye shes mtsho rgyal and shar tho Me ri mkha' 'gro. (6.08 p. m.) The introductory prayers begin. Soon, however, he begins to sing accompanying himself with drum and gshang. As the singing goes on, the drumming becomes louder and his face grows paler and tighter. His eyes are closed. (6.35 p.m.) He stops singing and puts down his instruments. He takes a piece of red cloth and ties it around his head. Then he drums and tinkles violently for a short while. He puts down his gshang and takes up his headdress with his left hand and holds it up in front of him, while increasing the drumming. (6.42 p.m.) He puts the drum down and holds his headdress in both hands, while he sings. Then he binds it to his head, groaning and snorting. After this he starts the violent drumming again and jumps out on the floor. He dances in front of the altar and then kneels facing it. Then he jumps back up on the bench. From there the god, who is Ma sangs rkyang khra mchor bo, now asks why he is wearing the headdress and why he has been asked to come on this inauspicious day. He orders the questions to be put without delay and without lies. In the meantime, the intermediary appointed for the evening has lighted incense-sticks and put them on the altar. He now takes a kha btags and holds it in the smoke from the sticks before he puts it over $N y i$ ma don grub's headdress. He then, with great politeness, asks the god to help the sick youth. Nyi ma don grub begins singing to a rather slow drum-rhythm. He first tells us about the gods, whom he can see in the mirrors. He then proceeds to describe the cave of Mount Targo in which there are the three copper-ladders that play such a 
significant role in one of the versions of the initiation procedure of spiritmediums (cf. Berglie 1980:40). The god then says that he has now borrowed a body that is like a hollow tree and that it does not belong to one of the best $d p a^{\prime}$ bos but neither to one of the worst. As he sings, he rises to a kneeling position. Then he takes a few grains of rice and says he is going to perform rtsis, i.e. drum divination. He also describes the three members of the lha-class, who will supervise the procedure. $(7.00 \mathrm{p} . \mathrm{m}$.) He puts the drum on a small table in front of him and places the rice on the drumskin. $\mathrm{He}$ asks the onlookers to watch closely. When he then starts to sing and tinkle with the gshang, the grains start to move towards the altar. The intermediary tells the god what is happening. Nyi ma don grub then flips the grains away from the drum-skin with his index-finger, takes up the drum and starts drumming. In rapid succession he then performs two further divinations, now using only one grain at a time. The first time the grain moves noticeably towards the altar, but the second time there are different opinions among those present as to how and if the grain moved. The intermediary has a hasty discussion with one of the onlookers, and it is agreed that he is to tell the god that the grain rotated clockwise, the auspicious direction. When this has been done, Nyi ma don grub takes his instruments and starts the music and the song. He now sings about the young man's illness, explaining that it has been caused by eating meat of different kinds and by drinking "bad" chang, rice-beer. The intermediary then asks the god to do what has to be done. The god accordingly asks the patient to sit down in front of him. $(7.12 \mathrm{p} . \mathrm{m}$.) The god says he is going to expel a demon, 'dre, from the body of the patient. The onlookers arrange themselves so that there is a free passage from the patient to the door. Then Nyi ma don grub presses the patient's body in the chest and in the back with his drum and bell. (7.20 p. m.) The god again mentions the causes of the man's illness: he has eaten meat, drunk chang from unclean cups etc. Then he feels the patient's pulse at a point on the forearm. He starts to sing again, saying that the illness is going to be sucked out but, as the borrowed body (i.e. Nyi ma don grub) has not yet learned this, it is going only to be an experiment. The intermediary takes a piece of red cloth, while the god summons Zangs spyang dmar po. Soon Nyi ma don grub starts a violent drumming and begins to growl and howl. The red cloth is placed on the naked back of the patient. Nyi ma don grub now wears a very fierce expression on his face as he growls menacingly. Suddenly he grabs the red cloth with a swift movement of his right hand and then puts it into his mouth. He chews and swallows and then puts the cloth back. Then he sucks through his drum, having placed it on its edge against the cloth. $\mathrm{He}$ spits out into a small bowl of water. The content of the bowl is then 
inspected by the intermediary and several onlookers and there follows a discussion on what is to be seen. To me it looks like small greyish particles dissolving in the water. The god is told the result of the discussion and starts to sing, pausing only to swallow the content of the bowl. $(7.46 \mathrm{p} . \mathrm{m}$.) The patient dresses when the god asks for a red-hot iron. He is told that there is not such a thing in the house, and so he takes a ribbon of red cloth and ties a knot in it while he whistles. He soaks the ribbon with oil and sets it on fire. He then puts the burning ribbon into his mouth three times, every time spitting on the patient's back. After a short song he repeats the procedure another three times, now spitting over different parts of the patient's body. Then the god, singing and talking alternatively, gives him good advice. He then takes another ribbon and holds it up in front of the altar, before giving it to the patient to keep and wear around his neck as a blessing. (7.55 p.m.) The cure has now been effected and the patient withdraws into a corner of the room, while Nyi ma don grub proceeds to the concluding part of the séance. He shakes his head vehemently as he sings. The intermediary refills the oil-lamp on the altar and also lights some incense-sticks. The kha btags, which was put over the rigs lnga at the beginning of the possession, now slides off but is put back by the intermediary. The gods are now leaving the place. The intermediary, however, cannot keep up with $N y i$ ma don grub's pace and therefore fails to give some of the gods their drops of tea as a farewell offering. For this he receives scornful remarks from the god. $(8.10 \mathrm{p} . \mathrm{m}$.) The concluding part of the séance is now well under way, with Nyi ma don grub making violent movements of the head and upper part of his body. The singing is now and then interrupted by snorting. He leans to the right and to the left so that the wings of his headdress cover his face. The headdress is now slowly sliding backwards. ( 8.29 p.m.) The headdress falls off his head and stays around his neck. He snorts loudly. He is slumping backwards in a sitting position, while his head falls forward against his chest. The séance is over."

\section{Concluding remarks}

In the notes on séances given above, only the external procedures have been recorded. What, on the other hand, the spirit-mediums themselves experienced, they found hard to describe. When they sang the invocations, which mostly consisted of names of gods interspersed with urgings and pleadings for them to come to the place, they could see the gods arrive, some of them riding on birds, others on horses. They also saw them dismounting, putting away their saddles, weapons etc. and arranging themselves according to rank. This ability to see the gods in the mirrors is not, however, restricted to spirit-mediums, I was told. Lamas and sngags pas 
are also supposed to have it. When all the gods summoned have arrived, possession took place by the god most suited to carry out the task of the evening. dBang phyug said that he then saw all the colours of the rainbow in the mirrors and that all became very bright when the gods arrived. When then the god was to take possession of him, his body felt enlarged and as if filled with air. Sri gcod said that when his rnam shes was going to leave his body, he saw a glowing fire of many colours. This fire grew bigger and bigger and finally entered his body, as it were. After that, everything became black and he remembered nothing further. At the end of the possession all this happened in the reversed order. Nyi ma don grub was able to give a somewhat more detailed relation. Every time he sang the invocations, he said that he saw three stars in the mirror: one white, one red, and one blue. They corresponded to the three classes of gods: the tha-, the btsan-, and the $k l u$-class respectively. During the introductory part of the séance his experiences of his surroundings were altered. The people in the room seemed to become smaller and smaller, while their voices became thinner and squeakier. Their eyes became brighter and glittered and shone. The mirrors on the altar, on the other hand, grew larger and larger and finally filled his entire field of vision.

The actual change of the ritual status of the spirit-medium is marked by the putting on of the headdress. From now on, until it falls off at the end of the séance, it is the god who speaks and acts through the medium, who afterwards claims that he has no recollection whatsoever of what then passes. The onset of the possession is also marked by motoric agitation, sometimes of a violent nature, as often in the case of Nyi ma don grub, followed by a dance on the floor or on the sitting-bench. dBang phyug said that there were different dances, e.g. the dance of the mkha' 'gro ma, of the elephant etc., but could not give any details. After dancing the god usually sits down, introduces himself and asks, often in very rude and offensive language, why he has been called. From then on the séance moves on as outlined above.

A necessary condition for the activity of a spirit-medium is, of course, the conviction that their possession is genuine. Theoretically, when a $d p a$ ' bo has passed the period of calling and has been tested and has received the necessary training, this genuineness is proved (cf. Berglie 1976:88-93). Of an established $d p a^{\prime}$ bo no further proofs are therefore required in addition to the satisfactory solution of the problems put to him at the séances. If, after all, someone has doubts about a $d p a^{\prime}$ bo, he can call a lama, a sngags $p a$, or another $d p a^{\prime}$ bo and let him look into the mirrors to make sure that it is gods who have arrived and not demons in disguise. No such check, I was told however, had ever been made in the village. In spite of this, it is hard to 
avoid the impression that the spirit-mediums felt a continuous need to prove the reality of the possession. As mentioned above, rather spectacular features were often added to the séances, although not necessarily required. I am referring to the throwing of glowing charcoal and the playing with fire in the séances of Nyi ma don grub and to the falling of thang dkarfeathers in the séances of $d B a n g$ phyug. All religious rites and ceremonies do of course exhibit varying degrees of theatricality and the séances of the $d p a$ ' bos, largely 'one-man-shows", are no exception. Although features such as those mentioned perhaps more properly belong to this dimension, they can also be ascribed to a medium's aspiration to show the audience the powers of the gods and impress on it the reality of their presence. This must not be regarded as overshadowing the main aspect of every séance, which is that of a serious and purposeful ceremony in which the principal actor, the possessing god, is treated with trust and humility.

In another study I have tried to show that beliefs in possessional states are to be found at many levels and in many contexts in Tibetan religion (cf. Berglie in press). They involve consciousness-transference of one kind or another and are, as in the case of the $d p a^{\prime}$ bos, expressed in Indian Buddhist terms. To these spirit-mediums and to their clients and audience therefore, possession is neither anything mysterious or inexplicable nor anything demanding analysis and speculation. Their séances were, normally, well-ordered procedures where nothing unexpected was likely to happen if the $d p a^{\prime}$ bo knew his procedure.

\section{References}

Berglie, P.-A. 1976. Preliminary remarks on some Tibetan "spirit-mediums" in Nepal. Kailash, a journal of Himalayan studies 4, 1, 85-108.

- 1978. On the question of Tibetan shamanism. Tibetan Studies, ed. by M. Brauen and P. Kvaerne, 39-51. Zürich.

- 1980. Mount Targo and Lake Dangra: a contribution to the religious geography of Tibet. Tibetan Studies in Honour of Hugh Richardson, ed. by M. Aris and Aung San Suu Kyi, 39-44. Warminster.

- in press When the corpses rise: some Tibetan Ro langs stories. Indologica Taurinensia 9. Torino.

Dasgupta, S. B. 1958. An introduction to Tantric Buddhism. Calcutta.

Eliade, M. 1969. Yoga: immortality and freedom. (Bollingen Series 56.) New York.

Govinda, A. 1959. Foundations of Tibetan mysticism. London.

Snellgrove, D. L. 1957. Buddhist Himalaya. Oxford.

- 1959. The Hevajra Tantra 1. (London Oriental Series 6.) London.

Stablein, W. 1976. Tantric medicine and ritual blessings. The Tibet Journal 1, 3/4, 55-69. 
Tucci, G. 1961. The theory and practice of the Mandala. London.

- 1970. Die Religionen Tibets. Die Religionen Tibets und der Mongolei 1-291. (Die Religionen der Menschheit, ed. by C. M. Schröder. 20.) Stuttgart.

Wayman, A. 1973. The Buddhist Tantras: light on Indo-Tibetan mysticism. New York.

- 1977. Yoga of the Guhyasamājatantra. Delhi. 